\title{
CONTRIBUIÇÕES DA PESQUISA COLABORATIVA NA FORMAÇÃO DO DOCENTE DE SALA DE APOIO À APRENDIZAGEM DE LÍNGUA PORTUGUESA
}

\author{
Cristiane Malinoski Pianaro ANGELO \\ Universidade Estadual do Centro-Oeste \\ Renilson José MENEGASSI \\ Universidade Estadual de Maringá
}

\begin{abstract}
RESUMO: Este trabalho discute as contribuições da pesquisa colaborativa na formação docente contínua no contexto de uma Sala de Apoio à Aprendizagem de Língua Portuguesa SAALP, $6^{\circ}$ ano do Ensino Fundamental, na região Centro-Sul do Estado do Paraná. Tem-se como objetivo refletir como a mediação pedagógica colaborativa, por meio de orientações teórico-metodológicas sobre leitura e escrita, auxilia na prática efetiva da docência e na aprendizagem na SAALP. A pesquisa é realizada à luz da Linguística Aplicada, embasada nos pressupostos do dialogismo, a partir do Círculo de Bakhtin, na teoria histórico-cultural, privilegiando-se os aportes de Vygotsky e Leontiev, e nas concepções de processo de leitura e escrita abordadas por Menegassi. Emprega-se como procedimento de investigação a pesquisa colaborativa, visto que se buscou uma relação colaborativa com um professor da SAALP, auxiliando-o, por meios de diversas ações colaborativas, a refletir sobre a própria prática no trabalho com a língua materna, a construir novos conhecimentos a respeito do processo de leitura e de escrita, a planejar ações em prol da melhoria da qualidade do ensino e da aprendizagem em SAALP, a alterar as ações cotidianas em sala de aula, a diagnosticar os problemas e os efeitos das mudanças nesse contexto de ensino. Os resultados das análises demonstram: a) a internalização e a apropriação dos pressupostos teórico-metodológicos concernentes aos processos de leitura e escrita pelo docente; b) o aprimoramento no desenvolvimento da leitura e da escrita dos alunos da SAALP; c) a necessidade de se fornecer ao professor de SAALP subsídios teórico-metodológicos quanto ao trabalho com a leitura e a escrita, bem como acompanhar e orientar a sua prática pedagógica nesse contexto específico de ensino.
\end{abstract}

PALAVRAS-CHAVE: Formação docente contínua; pesquisa colaborativa; Sala de Apoio à Aprendizagem de Língua Portuguesa; processos de leitura e de escrita

\begin{abstract}
This paper discusses the contributions from collaborative research in the continuous teacher formation practice in the context of Support Classroom for Portuguese Language Learning (SAAPL, in Portuguese), $6^{\text {th }}$ grade of basic schooling, in the SouthCentral region of Parana State. The main goal of this work is to reflect on how the collaborative educational mediation, by means of theoretical-methodological guidance about reading and writing, helps to achieve an effective practice for the teacher and for the learning process in a SAALP. The research is build upon the concepts of the Applied Linguistics field, based on the dialogism assumptions from Bakhtin Circle, in the historical-cultural theory, favouring the contributions of Vygotsky and Leontiev, and on the concepts of reading and writing processes proposed by Menegassi. As an investigation procedure, it is employed the collaborative research, considering that the researcher aimed to develop a collaborative
\end{abstract}


relation with the SAALP's teacher, helping him, by means of many collaborative actions, to reflect on his own practice with his mother tongue, to construct new ideas about the reading and writing processes, to plan actions towards the quality improvement of the teaching and learning processes in a SAALP, to change daily actions in the classroom, to diagnose the problems and the effects of changes in this teaching context. The results obtained point to: (a) the internalization and the comprehension of the theoretical-methodological assumptions related to the reading and writing processes, by the teacher; (b) the improvement in the development of reading and writing of the SAALP students; (c) the necessity of providing the SAALP teacher theoretical basis and methodological guidance to work with reading and writing, as well as monitor and guide their practice in that particular teaching context.

Keywords: Continual teacher formation; collaborative research; Support Classroom for Portuguese Language Learning (SAAPL); reading and writing processes.

\section{Introdução}

Saber fazer uso da leitura e da escrita nas diversas circunstâncias de interação social consiste, na atualidade, em uma situação inquestionável tanto para a construção do ser e o fortalecimento do exercício da cidadania, no plano individual, como para a melhoria do desenvolvimento de uma nação, no plano sócio-político-cultural. De acordo com Mortatti, "é dever do Estado proporcionar, por meio da educação, o acesso de todos os cidadãos ao direito de aprender a ler e a escrever como uma das formas de inclusão social, cultural e política e de construção da democracia" (2004, p. 15). Assim, as práticas de leitura e escrita são fatores condicionantes para a promoção de valores democráticos, porque ampliam no ser humano as possibilidades de atuação no mundo e, consequentemente, contribuem para qualificar as relações humanas e solucionar tanto os problemas sociais cotidianos quanto os mais complexos.

Entretanto, no contexto brasileiro, muitos têm sido os percalços para que se cumpra plenamente esse dever do Estado. Conforme dados apresentados em matéria da revista "Gestão Escolar":

A evasão, a repetência e a não-alfabetização no tempo correto são tão comuns no Brasil que têm estado presentes nos últimos Planos Nacionais de Educação (PNE). O que expirou em 2010 pretendia a redução em 50\% das taxas de abandono e repetência, o que foi cumprido em parte: $\mathrm{o}$ abandono foi reduzido conforme o planejado, mas a reprovação aumentou de 11 para $12,1 \%$ no mesmo período ${ }^{1}$.

De acordo com os Parâmetros Curriculares Nacionais - PCN (BRASIL, 1998), o problema da repetência vincula-se diretamente à dificuldade da escola em ensinar a ler e a escrever, expressando-se com maior nitidez nos dois primeiros anos, em virtude da dificuldade em alfabetizar, e no $6^{\circ}$ ano, por não se conseguir garantir o uso eficaz da linguagem escrita, condição para que os alunos possam continuar a progredir até, pelo menos,

\footnotetext{
${ }^{1}$ Fonte: GESTAO ESCOLAR, Edição 017, Dezembro 2011/Janeiro 2012. Título original: Um plano de metas para 2013. Disponível em http://gestaoescolar.abril.com.br/aprendizagem/plano-metas-atingir-2012648531.shtml. Acesso em 24/06/2014.
} 
o fim do $9^{\circ}$ ano do Ensino Fundamental, segundo se aponta nos Parâmetros Curriculares Nacionais - PCN (BRASIL, 1998).

No Plano Nacional de Educação - PNE em vigor no Brasil, indicador dos rumos da educação brasileira até 2024, são sugeridas iniciativas interventivas por parte do poder público para o enfrentamento dos problemas de repetência, evasão e má qualidade do ensino, por exemplo:

Manter e ampliar programas e ações de correção de fluxo do ensino fundamental, por meio do acompanhamento individualizado do (a) aluno (a) com rendimento escolar defasado e pela adoção de práticas como aulas de reforço no turno complementar, estudos de recuperação e progressão parcial, de forma a reposicioná-lo no ciclo escolar de maneira compatível com sua idade. $^{2}$

No âmbito do Paraná, destacamos, como medida interventiva, o Programa Sala de Apoio à Aprendizagem - SAA, o qual consiste em uma política educacional que foi instituída em 2004 com o intuito de propiciar a efetivação e a proteção ao direito que os alunos do Ensino Fundamental têm de obter uma educação de qualidade, resolvendo ou minimizando suas dificuldades de aprendizagem e estendendo seu tempo de escolaridade. Nos termos da Resolução no 208/04 - da Secretaria Estadual de Educação do Paraná - SEED/PR, que implementou o Programa, a SAA consiste em uma iniciativa pedagógica "para enfrentamento dos problemas relacionados ao ensino de Língua Portuguesa e Matemática e às dificuldades de aprendizagem, identificadas nos alunos matriculados na $5^{\mathrm{a}}$ série $\left[6^{\mathrm{o}}\right.$ ano] do Ensino Fundamental, no que se refere aos conteúdos de leitura, escrita e cálculo" (Art. $1^{\circ}$ ). Os alunos incluídos no Programa frequentam aulas de Língua Portuguesa e/ou Matemática no contraturno, participando de atividades em prol da reversão do insucesso no aprendizado dos conteúdos dessas disciplinas.

Embora os referenciais normativos do programa apregoem a necessidade de se promover a formação contínua para os profissionais envolvidos no Programa, não há, na prática, um conjunto de ações voltado a essa formação, de modo a orientá-los acerca dos objetivos da SAA, bem como sobre os conteúdos e as especificidades dos encaminhamentos metodológicos a serem adotados. Além disso, pesquisas desenvolvidas por Angelo (2007), Angelo e Fracasse (2009) e Duarte (2011) apontam que o caderno "Orientações pedagógicas" - único material disponibilizado aos professores e alunos da SAALP e que desde a criação do Programa não passou por qualquer revisão - apresenta muitas limitações, pouco contribuindo para auxiliar o professor no atendimento aos alunos com histórico de defasagens na leitura e na produção escrita.

\footnotetext{
${ }^{2}$ Fonte: LEI 13.005, de 25 de junho de 2014. Aprova o Plano Nacional de Educação - PNE e dá outras providências. Disponível em http://pesquisa.in.gov.br/imprensa/jsp/visualiza/index.jsp?data=26/06/2014\&jornal=1000\&pagina=1\&totalArqui vos $=8$. Acesso em 30/09/2016.
} 
Avaliamos, assim, que falta, para esse contexto de ensino, um programa de formação contínua, capaz de auxiliar o professor na tomada de decisões em busca da superação das dificuldades de aprendizagem por parte dos alunos que frequentam a SAALP.

Compreendemos a formação contínua, ou formação em serviço, como um trabalho de reflexibilidade crítica a respeito da teoria e da prática pedagógica visando à mudança e à transformação na conjuntura escolar. Segundo Imbernón, esse trabalho deve apoiar, criar e potencializar uma reflexão real dos sujeitos sobre sua prática docente nas instituições educacionais, de modo que lhes permita "examinar suas teorias implícitas, seus esquemas de funcionamento, suas atitudes, etc., estabelecendo de forma firme um processo constante de autoavaliação do que se faz e por que se faz" (IMBERNÓN, 2010, p. 47), em direção a alterações de suas condutas pedagógicas.

Ao explorarmos algumas pesquisas que abordam a formação contínua do professor, percebemos que essa modalidade de formação é alvo de muitas críticas, em virtude da maneira como são conduzidas e concebidas. O Estado da Arte sobre as políticas docentes no Brasil, realizado por Gatti, Barreto e André (2011), identificou que as ações de formação contínua no país constituem-se geralmente de realização de oficinas, palestras, seminários e cursos rápidos, presenciais e a distância, oferecidos pelas secretarias de educação ou decorrentes de contratos firmados com instituições universitárias ou de pesquisa, prevalecendo-se uma concepção de formação transmissiva. Também, Imbernón (2010) afirma que há, nesse processo, muita formação e pouca mudança, pois ainda predominam propostas de formação e formadores que exercem uma formação autoritária e uniforme, com predomínio de uma teoria fora de contexto, aplicável a qualquer situação e distante de problemas práticos reais. Nessa mesma linha, Loureiro assinala que ocorre no sistema de formação contínua em curso uma evidente "desarticulação com as reais necessidades criadas pelas mudanças no sistema educativo" (1997, p. 151), o que não traz contribuições para a constituição de sujeitos ativos e transformadores da escola.

Essas reflexões sugerem alguns direcionamentos para a formação contínua do professor da SAALP, para não a concebermos como um ato de transferência, como um conjunto de atividades isoladas e desvinculadas das urgências do contexto escolar, mas como uma ação de imersão na realidade, de reflexibilidade e de coconstrução de conhecimentos. Nesse sentido, Silveira (2009) aponta a importância de se delimitar, junto aos professores, objetivos nítidos para cada formação e que essa não ocorra esporadicamente, mas de forma contínua, contemplando momentos de acompanhamento da prática docente de maneira particular, no cotidiano das escolas e das salas de aula.

Para atender essa necessidade, entendemos que a pesquisa colaborativa consiste numa ferramenta adequada para ser utilizada na formação do docente para a SAALP, visto que, em consonância com autores como Pimenta (2005), concebemos essa modalidade de pesquisa como um processo de construção de conhecimentos em que o pesquisador, como par mais experiente do processo, intervém no próprio espaço escolar, diagnosticando problemas e propondo desafios, reflexões, mudanças, de modo que o sujeito pesquisado, ou seja, o professor colaborador, conscientize-se das transformações que vão ocorrendo em si próprio e no processo e, dessa forma, desenvolva a sua autonomia docente.

A pesquisa colaborativa encontra seus fundamentos principais na perspectiva histórico-cultural (VYGOTSKY, 1994), na qual se concebe que o conhecimento se forma no interior das relações sociais, evidenciando-se, assim, o papel do outro como mediador 
colaborativo do processo de construção dos saberes. Segundo Oliveira, a mediação caracteriza-se como uma "categoria que se consolida no movimento de articulação das coisas funcionando como o centro organizador das relações sociais. Não é uma categoria instrumental, mas existe para a compreensão de um movimento da realidade objetiva, no caso as relações sociais" (2009, p. 38, grifos nossos). Nessa perspectiva, a mediação colaborativa, nesta pesquisa, caracteriza a relação do pesquisador com o professor colaborador no processo de análise, reflexão, decisão, redimensionamento, organização, planejamento, execução e avaliação das ações pedagógicas no contexto da SAALP.

Em exames de publicações e produções acadêmicas, observamos que não há investigações que abordem a formação de docentes para a SAALP. Os poucos trabalhos de pesquisa voltados a esse contexto tratam do material didático - o caderno "Orientações Pedagógicas", ou apresentam um diagnóstico do Programa ou, ainda, expõem investigações de natureza interventiva em SAA, deixando-se nítida uma lacuna para pesquisas que abordem a formação de docentes para as SAALP.

A partir dessas considerações, temos por objetivo refletir, neste artigo, como a mediação pedagógica colaborativa, por meio de orientações teórico-metodológicas sobre leitura e escrita, auxilia na prática efetiva da docência e na aprendizagem na SAALP.

Além de fundamentar-se nos princípios metodológicos da pesquisa colaborativa e na teoria histórico-cultural, a pesquisa embasa-se nos pressupostos do dialogismo, a partir do Círculo de Bakhtin, especificamente dos trabalhos de Bakhtin/Volochinov (1999[1929]) e Bakhtin (2003[1979]), e nas discussões acerca dos processos de leitura e escrita (MENEGASSI, 2010a; 2010b), reconhecendo-se que esses processos são primordiais para o desenvolvimento dos alunos como sujeitos leitores e produtores de textos. Ao se considerar que o conceito de processo sugere algo que propicia um estado de transformação (RODRIGUES, 2013), podemos entender que conduzir o aluno pelas etapas que compõem os processos de leitura e de escrita leva-o a apropriar-se de modo gradativo da construção do processo, a perceber a evolução dos próprios conhecimentos. Segundo Menegassi (2010a; 2010b), as etapas desses processos ocorrem de forma concomitante e recursiva, dependendo uma da outra para sua realização, propiciando um conjunto harmônico de estratégias e habilidades no leitor e produtor de textos. No que se refere à SAALP, compreendemos que o trabalho com os processos de leitura e de escrita mostra-se pertinente ao proporcionar condições para que o aluno supere suas dificuldades aos poucos, progressivamente, dando-lhe confiança e segurança ao entender que é capaz de produzir suas próprias palavras na leitura e na produção textual (BAKHTIN/VOLOCHINOV, 1999[1929]).

\section{O processo colaborativo na formação do docente de SAALP}

Em consonância com características da pesquisa colaborativa, a investigação constituiu-se de três etapas: 1) diagnóstico inicial; 2) ações colaborativas junto ao professor e o monitoramento da prática em sala de aula; 3 ) diagnóstico final.

Na primeira etapa - diagnóstico inicial, levantamos a situação de leitura e escrita dos alunos da SAALP, bem como buscamos constatar os conhecimentos internalizados pelo professor no que se refere à leitura, à escrita e seu processo de ensino, para que assim 
pudéssemos constatar que ações colaborativas se fariam necessárias desenvolver junto ao professor para a melhoria da qualidade de ensino e de aprendizagem proporcionada no contexto da SAALP.

Constatamos que a leitura em sala de aula distanciava-se dos pressupostos dialógicos de linguagem, ao configurar-se como uma sequência de ações isoladas: $1^{\circ}$ ) o aluno oraliza o texto; $2^{\circ}$ ) o professor explica o lido ou promove discussões alheias ao texto; $3^{\circ}$ ) o aluno atribui respostas a perguntas de elaboração pessoal (SOLÉ, 1998), repetindo a explicação do professor ou baseando-se exclusivamente em suas opiniões e conhecimentos prévios, como demonstra a tarefa solicitada aos alunos, referente à fábula "O rato do campo e o rato da cidade",

Responda:

a) Na fábula "O rato do campo e o rato da cidade", o rato da cidade tem mais dificuldade para conseguir comida. Você concorda com essa ideia?

C3 - "Sim. Por na sidade e muito"

B1 - "Sim. Na cidade depende do dinheiro."

b) $\mathrm{Na}$ história, o rato da cidade julga a alimentação do campo muito fraca (ruim, insuficiente). Você concorda?

C3 - "Não poque era sadaver"

B1 - "Não. Por que a comida da sidade era salgada."

c) Você concorda que existe uma dependência entre o campo e a cidade?

C3 - "Sim, poque o xxxx do capo va pacidade."

B1 - "Sim."

Verificamos que as respostas dos alunos - considerando que, nesta pesquisa, o gênero textual resposta é uma prática de linguagem que se concretiza na esfera escolar, normalmente em situação avaliativa - configuram-se como enunciados fragmentados, na maioria das vezes recortados do texto, que não informam ao leitor a compreensão e a interpretação obtidas na interação com o texto. Também, apresentam diversos desvios de ordem ortográfica, coesiva e de pontuação.

Ao tomarmos os pressupostos vygotskianos concernentes à aprendizagem, uma vez que entendemos o processo de formação contínua como um processo de aprendizagem, buscamos focalizar as ações de formação nas funções ainda não amadurecidas, mas em processo de maturação, ou seja, assumimos como fio condutor da pesquisa colaborativa o Nível de Desenvolvimento Potencial - NDP (VYGOTSKY, 1994) do professor, caracterizado como as capacidades em vias de serem construídas por meio da interação com outros sujeitos. Consideramos, por exemplo, que o professor tem como conhecimento aprendido e dominado - o NDR, a necessidade de trabalhar com o aluno o processo interpretativo, que exige a intervenção dos saberes prévios e da opinião do leitor, faltando-lhe solidificar conhecimentos, com auxílio de outros sujeitos - o NDP, acerca de outras etapas do processo de leitura, como o reconhecimento de informações e a compreensão inferencial, necessárias à etapa da interpretação.

A segunda etapa - Ações colaborativas junto ao professor e o monitoramento da prática em sala de aula - constituiu-se a base principal da pesquisa, pois evidenciou como a mediação colaborativa, como as orientações teórico-metodológicas concernentes aos 
processos de leitura e de escrita, na situação da SAALP, repercutem no ensino e na aprendizagem nesse contexto, auxiliando o docente a refletir, avaliar, redimensionar, tomar decisões, planejar, conduzir e monitorar o trabalho com a leitura e a escrita junto a alunos que apresentam dificuldades de aprendizagem.

Assim, com o objetivo de: a) intervir na ZDP do professor, promovendo reflexões a respeito do caráter processual da leitura e da escrita e b) instigar o professor à elaboração e aplicação de atividades de leitura e escrita, tendo em vista os conhecimentos teórico-práticos adquiridos, proporcionamos ao sujeito participante da pesquisa - o professor da SAALP leituras de textos teóricos e metodológicos, orientadas por um roteiro de discussão, bem como desenvolvemos sessões reflexivas em que alguns aspectos do texto e do roteiro foram aprofundados nos diálogos entre pesquisadora e professor. Ao mesmo tempo, promovemos uma reflexão acerca da prática da pesquisa colaborativa em contexto de formação contínua, tanto nos aspectos de escolha do material e de elaboração de atividades para o professor, como também na condução das sessões reflexivas.

Para o desenvolvimento das ações colaborativas junto ao professor e monitoramento da prática em SAALP, utilizamos diversos instrumentos, os quais são apresentados no Quadro 1 :

Quadro 1: Instrumentos utilizados nas ações colaborativas, com seus respectivos objetivos e período de realização

\begin{tabular}{|c|c|}
\hline $\begin{array}{l}\text { Instrumentos das ações } \\
\text { colaborativas }\end{array}$ & Objetivos \\
\hline Textos teórico-metodológicos & $\begin{array}{l}\text { Favorecer a construção de conhecimentos sobre o caráter processual da } \\
\text { leitura e da escrita. }\end{array}$ \\
\hline $\begin{array}{l}\text { Plano de discussões teórico- } \\
\text { metodológicas para a SAALP }\end{array}$ & $\begin{array}{l}\text { Orientar a leitura dos textos teóricos, propondo desafios, instigando o } \\
\text { professor à reflexão e à criticidade. }\end{array}$ \\
\hline Sessões reflexivas & $\begin{array}{l}\text { Promover a reflexão teórico-prática em torno do processo de leitura e } \\
\text { de produção escrita. }\end{array}$ \\
\hline $\begin{array}{l}\text { Gravação de aulas com aplicação } \\
\text { de atividades modelares, presentes } \\
\text { nos roteiros de discussão e } \\
\text { discutidas nas sessões reflexivas }\end{array}$ & $\begin{array}{l}\text { Verificar de que forma o professor internalizou os conhecimentos } \\
\text { obtidos com a leitura dos textos teórico-práticos, com as atividades dos } \\
\text { roteiros de discussão e com a participação nas sessões reflexivas. }\end{array}$ \\
\hline $\begin{array}{l}\text { Roteiro de monitoramento a } \\
\text { respeito das atividades aplicadas em } \\
\text { SAALP e sessão de avaliação }\end{array}$ & $\begin{array}{l}\text { Instigar o professor a uma reflexão sobre a própria prática. } \\
\text { Intervir em aspectos teórico-práticos da leitura e da escrita ainda não } \\
\text { dominados pelo professor. }\end{array}$ \\
\hline $\begin{array}{l}\text { Atividades elaboradas pelo } \\
\text { professor }\end{array}$ & $\begin{array}{l}\text { Verificar de que forma o professor internalizou os conhecimentos } \\
\text { obtidos ao longo das ações colaborativas. }\end{array}$ \\
\hline Gravação de aulas & $\begin{array}{l}\text { Verificar de que forma o professor internalizou os conhecimentos } \\
\text { obtidos ao longo das ações colaborativas. }\end{array}$ \\
\hline
\end{tabular}

Fonte: organizado pelos autores.

Trazemos para discussão um momento das sessões reflexivas, em que discutimos com o professor as etapas processo de leitura. Essa discussão ocorreu a partir da leitura do texto "O leitor e o processo de leitura" (MENEGASSI, 2010a) e das respostas dadas pelo professor a um roteiro de leitura.

Inicialmente, ao ser questionado acerca das diferenças entre a decodificação fonológica e decodificação ligada à compreensão - conceitos presentes no texto em discussão - o professor apenas elencou algumas expressões retiradas do texto, sem formular uma 
explicação coerente: "Eu só anotei aqui... decodificação fonológica... a questão significado significante... a palavra versus a imagem... né? Seria a decodificação fonológica...”. No que se refere à compreensão literal, o professor assim se pronunciou: "Então eu anotei algumas coisinhas aqui... a compreensão literal seria tirar a ideia principal do texto... então isso seria a compreensão literal...". Essas exposições evidenciam as dificuldades do professor em mobilizar os conceitos relativos ao processo de leitura a partir do primeiro contato com o texto, o que nos forçou a tecer explicações, citar exemplos, voltar ao texto teórico e reler alguns fragmentos.

Entendemos que essas dificuldades se devem porque o professor não se constituiu, em sua formação inicial e contínua, como um leitor competente, reflexivo, crítico, que vai ao encontro do conhecimento, mas como um repetidor de modelos, de atividades de livros didáticos, de conceitos teóricos. Assim, sem interagir constantemente com o conhecimento, sem refletir a respeito da prática pedagógica, por meio de leituras críticas, compartilhadas, reflexivas, o professor tende a formar também alunos repetidores, que não dialogam com o lido, que não tiram conclusões, que não expandem o conhecimento. Esses debates reforçam a importância do desenvolvimento da colaborativa na situação de formação contínua, no intuito de possibilitar que o professor compreenda suas próprias práticas, produza significado e conhecimento que lhe possibilite a transformação das suas ações, gerando crescimento pessoal e o desenvolvimento de práticas democráticas (PIMENTA, 2005).

O Episódio seguinte retrata alguns fragmentos da discussão com o professor:

\footnotetext{
Episódio

Pesq. - (...) nós quando fomos alfabetizados... nós passamos muito por esse processo... só passávamos para a segunda série se nós estivéssemos lendo... e que era esse lendo? Lendo em voz alta... somente o processo de decodificação... e hoje o que se quer é o que o aluno leia e compreenda... né? Que seja uma decodificação aliada à compreensão... que ele leia e saiba o que ele está lendo... ou seja... reconhecer o código escrito e ligar com um significado...

Prof. - Isso é decodificação... compreensão... né?

Pesq. - Decodificação ligada à compreensão.... ligada então a essa segunda etapa... então importante que se compreenda que essas etapas não são separadas... elas estão ali unidas...

(...)

Prof. - E a compreensão com nível inferencial textual 'aquela que permite que se façam incursões no texto, captando informações que nem sempre estão em nível superficial...' então seria aquela parte em que o aluno lê mas vai além do que está propriamente dito ali?

Pesq. - Sim... um exemplo disso .... do que seria esse nível inferencial estaria numa frase como essa (anotando na folha de papel)... 'Ganhei uma bolsa nova e o fecho já estragou'... Não está escrito que o fecho é da bolsa... que as bolsas normalmente têm fecho// Cabe ao leitor fazer essa ponte... a inferência de que foi o fecho da bolsa que estragou.

Prof. - Então só com a decodificação o aluno não chega a inferências... ele lê por ler...né?

(...)

Prof. - Então... na verdade ... o término de uma etapa é o início da outra etapa... a decodificação aliada à compreensão chega na compreensão.... a compreensão extratextual chega na interpretação!?

Pesq. - Exatamente...

(...)

Pesq. - E a última etapa é a retenção ... é o que vai ficar pro aluno... o que ele vai armazenar em sua memória... após o término das etapas... ele pode armazenar informações que ele compreendeu e informações que ele interpretou...

Prof. - Memorizar o ponto de vista dele?

Pesq. - Segundo o autor... a retenção mais produtiva é a partir do que ele interpretou...

Prof. - Ele está criando alguma coisa... né?
} 
Com o uso da primeira pessoa do plural e compartilhando de uma mesma experiência com o professor - "nós quando fomos alfabetizados... nós passamos muito por esse processo... só passávamos para a segunda série se nós estivéssemos lendo...”, procuramos inserir ambos - o professor e a pesquisadora - no mesmo processo de elaboração do conhecimento, o que contribuiu para diminuir a assimetria entre professor e pesquisador, na qual este domina um saber e aquele, além de analisado, tenta aprender com este. Este procedimento aproximou-se de outra característica da pesquisa colaborativa: a necessidade de uma relação mais equilibrada entre pesquisador e professor colaborador (MATTOS, 2007). Também com intuito de abrandar a relação assimétrica entre os sujeitos, retomamos diversas vezes o autor do texto - "segundo o autor"; "para Menegassi" - e buscamos apreciar o material - "isso está bem explicado"; "Está bem definida ali na página 50”, deixando claro para o professor que não éramos nós, enquanto pesquisadora, que dominávamos o conhecimento, mas o autor do texto, no caso Menegassi (2010a).

Em virtude desses procedimentos, o professor expressa um engajamento maior na discussão, interessando-se em realizar comentários explicativos e em tirar conclusões, como, por exemplo, em: "Então só com a decodificação o aluno não chega a inferências... ele lê por ler... né?". Esse engajamento não evidencia ainda um amadurecimento por parte do professor, mas uma fase desse processo de amadurecimento, em que as falas são anunciadas ainda por perguntas que podem sugerir falta de confiança e/ou a busca por uma confirmação por parte da pesquisadora, a qual possuiria um conhecimento relativo à teoria.

Ainda no decorrer do trabalho colaborativo, o professor produziu e trabalhou em SAALP perguntas de leitura para uma crônica infantil. Reproduzimos o texto e as perguntas elaboradas:

\section{Bob Bafo}

Bob não gostava de escovar os dentes. E tinha um argumento para isso: dizia que seu bafo era terrível, que a noite ele matava qualquer mosquito que estivesse rondando sua cama com um simples "bah!fo". Quanto mais bala ele comia e mastigava sem escovar os dentes, mais podres os dentes iam ficando, e mais fedorento ia ficando o seu "bah!fo". Com o tempo, ele começou a matar moscas. Foi evoluindo para as lagartixas, até que chegou às baratas! Com dois "bah!fos", ele conseguia exterminar uma terrível barata cascuda de esgoto. Foi a consagração! Bob foi contratado por uma firma de dedetização e vai ficar por lá até que algum bom dentista se compadeça de sua boa boca. Bah! que bafo, meu!

(Diléa Frate. Histórias para acordar. São Paulo, Companhia das Letrinhas, 1997, p. 23)

Com base nas informações do texto, responda as questões abaixo:

1) Qual era a desculpa que Bob usava para não escovar os dentes?

2) O que Bob podia matar com seu bafo?

3) Por que os seus dentes iam ficando cada vez mais podres?

4) Após algum tempo, que outras coisas ele passou a matar com seu bafo?

Agora as respostas que você vai escrever são pessoais, ou seja, dependem de seu entendimento e interpretação do texto (suas opiniões):

1) No texto, Bob Bafo arrumou um emprego devido ao seu mau hálito. Você acha possível que isso aconteça nos dias de hoje? Justifique sua resposta.

2) Os adolescentes inventam desculpas para as coisas das quais não gostam ou julgam desnecessárias. Você lembra de alguma? Qual é a justificativa que eles usam?

3) Na sociedade, as pessoas têm acesso aos programas sociais gratuitamente, incluindo o tratamento dentário. Você sabe onde procurar por ter esse atendimento? Você já utilizou? Conhece outros tratamentos que são realizados gratuitamente? 
Com o desenvolvimento das sessões reflexivas, percebemos o processo de alterações na modalidade das perguntas. A mais saliente consiste na divisão das perguntas em dois blocos: "Com base nas informações do texto, responda as questões abaixo", em que as propostas requerem a interação com o texto para a busca das informações requisitadas; "Agora as respostas que você vai escrever são pessoais, ou seja, dependem de seu entendimento e interpretação do texto (suas opiniões)", inerentes à etapa da interpretação textual (MENEGASSI, 2010a).

Essas perguntas dão indícios do conhecimento construído pelo professor acerca das etapas do processo de leitura, o que se deu após uma série de eventos: a leitura do texto teórico, a resposta ao roteiro de discussão, a sessão reflexiva, elaboração da primeira versão de questões, nova sessão reflexiva, refacção das questões, nova sessão reflexiva, reelaboração das questões para aplicação em SAALP, e com o uso dos vários instrumentos expostos no Quadro1. Pimenta ressalta que "a pesquisa-ação crítico-colaborativa apresenta resultados de alterações das práticas ao longo do processo. Este, no entanto, requer tempo para se implantar e amadurecer" (2005, p. 536), como também requer modalidades distintas de eventos para que o conhecimento seja construído.

Ao assumirmos os pressupostos vygotskianos, entendemos que a qualidade do trabalho de formação contínua está vinculada à capacidade de promoção de avanços no desenvolvimento do professor. Para promover esses avanços, interviemos para ampliar e desafiar a construção de novos conhecimentos, incidindo na ZDP do professor. Dessa forma, estimulamos processos internos que futuramente se efetivarão, passando a constituir o alicerce que permitirá novas aprendizagens.

Na terceira etapa - Diagnóstico final - buscamos levantar o movimento de ensino da leitura e da escrita em SAALP, após as ações colaborativas. Participamos de aulas em que o professor trabalhou as perguntas de leitura, enfatizando as etapas do processo de leitura. Trazemos, para discussão, os esclarecimentos do professor no momento de orientar o aluno na seleção de informações apropriadas à produção das respostas: "Nós vamos fazer alguns exercícios... esses exercícios alguns vocês têm que voltar no texto... as respostas estão de acordo com o texto... e os outros são de interpretação... os de interpretação vocês encontram as respostas prontas no texto? (...) Interpretar é mostrar aquilo que aprendeu com o texto... no caso do texto que nós lemos, o filho não aprendeu alguma coisa!? Não interpretou aquela frase e colocou isso para a vida dele!?"; "pergunta de interpretação é baseada em meus conhecimentos e nas informações que o texto me traz... se o texto me deu várias informações mais aquilo que eu acho... aquilo que eu penso... mais as minhas informações... eu vou conseguir montar a minha resposta"; "Então tem respostas que você tem que voltar no texto... reler... e respostas interpretativas...que são as opiniões de vocês...”.

Esses comentários em sala de aula dialogam com as leituras e discussões efetuadas nas ações colaborativas, nas quais buscamos refletir o processo da leitura para que o professor adquirisse subsídios para desenvolver em SAALP um procedimento gradativo de apropriação dos sentidos possíveis no texto. Visualizamos, assim, que o professor mostra consciência das modalidades de perguntas, preocupando-se em diferenciar as perguntas de resposta textual das de resposta interpretativa - conforme percebemos na elaboração das perguntas para o texto Bob Bafo - situação bastante distinta da exposta no diagnóstico inicial, quando a organização das perguntas, apenas de nível interpretativo, não se fundamentava na concepção processual de leitura, portanto, não levava em conta as etapas que compõem o processo da 
leitura; quando, também, não se promovia em sala de aula qualquer orientação ou discussão quanto às modalidades de perguntas.

\section{Resultados comparativos}

Para que possamos estabelecer uma comparação entre o trabalho docente, antes das ações colaborativas, sem qualquer interferência teórica e metodológica da pesquisa, e o trabalho desenvolvido após as ações colaborativas, com suporte teórico e metodológico a respeito dos processos de leitura e escrita, elaboramos um quadro comparativo, a partir do qual podemos visualizar os avanços alcançados e as lacunas ainda persistentes no trabalho docente essa prática de linguagem em SAALP.

Quadro 2: Movimento docente de ensino da leitura e escrita

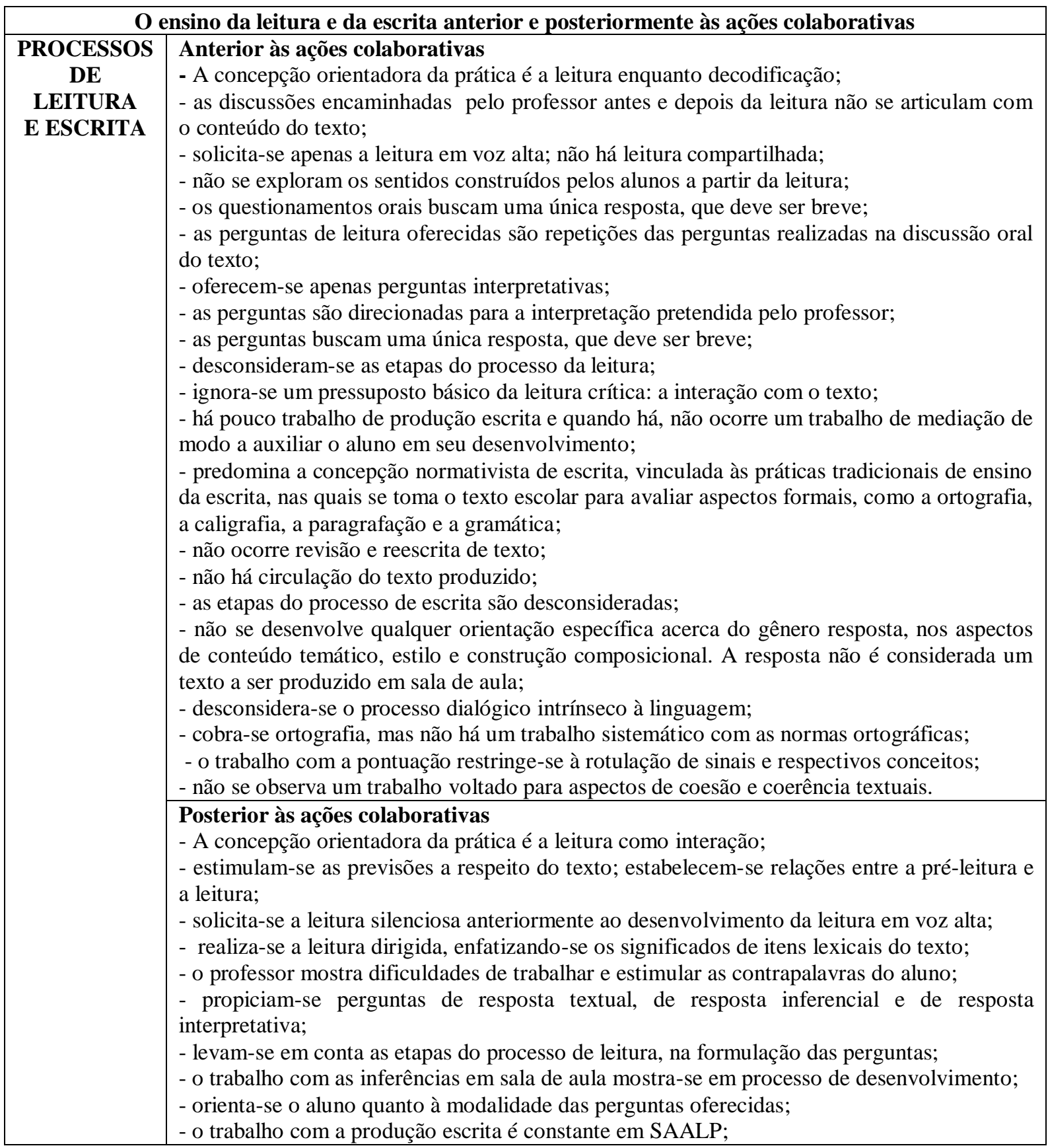




\begin{tabular}{|l|l|}
\hline - ocorre mediação do professor no trabalho de escrita; \\
- há preocupação com os elementos das condições de produção; \\
- considera-se as etapas do processo de escrita; \\
- no que se refere ao trabalho de revisão: a) ocorre durante e logo após a produção textual; b) \\
efetuada a partir da perspectiva do professor; c) o professor chama a atenção para o \\
problema na produção; d) propõe ao aluno alterar a forma de seu texto; e) orienta o aluno no \\
uso das operações linguístico-discursivas próprias do processo de reescrita; \\
- há um trabalho sistemático com relação à ortografia, pontuação e coesão; \\
- a resposta é considerada um texto a ser produzido e ensinado em SAALP: orienta-se o \\
aluno na construção composicional, solicitando-lhe a resposta completa.
\end{tabular}

Fonte: organizado pelos autores.

Constatamos que ocorreram alterações nas condutas do professor no trabalho com o processo de leitura e escrita em SAALP. Houve uma maior aproximação entre o texto e o aluno, propiciados pelas atividades de pré-leitura, na leitura dirigida, na discussão após a leitura, nas perguntas oferecidas para a produção das respostas escritas, no trabalho de produção textual das respostas. Dessa forma, a leitura, após as ações colaborativas, apresentou-se como um processo de interação entre texto e leitor, diferentemente da prática anteriormente às ações colaborativas, em que leitura se mostrava, apenas, como decodificação de letras em sons e meio de ocupar o tempo do aprendiz. No que se refere à produção escrita, não havia, antes do trabalho colaborativo, intervenções na etapa de execução da produção textual, como também não havia revisão e reescrita de texto. Após as intervenções da pesquisa, essas etapas passaram a fazer parte do processo de ensino da escrita em SAALP; assim, na revisão o professor chama a atenção para o problema na produção, propõe ao aluno alterar a forma de seu texto, orienta o aluno no uso das operações linguístico-discursivas próprias do processo de reescrita.

Demonstramos, também, no Quadro 3, como as ações colaborativas repercutiram no aprendizado dos alunos, evidenciando a situação de leitura e escrita antes das ações e depois das ações:

Quadro 3: Movimento discente de aprendizagem da leitura e da escrita

\begin{tabular}{|c|l|}
\hline \multicolumn{3}{|c|}{ O aprendizado da leitura e da escrita anterior e posteriormente às ações colaborativas } \\
\hline PROCESSO & Anterior às ações colaborativas \\
DE & - Os alunos, em sua maioria, apresentam dificuldades na localização de informações \\
LEITURA E & explícitas, na compreensão inferencial e na interpretação; \\
DE & - apresentam dificuldades na compreensão de enunciados de perguntas de leitura; \\
ESCRITA & - procuram recorrer à estratégia de pareamento, na construção das respostas a perguntas de \\
& leitura; \\
& - nas respostas a perguntas de leitura, apresentam respostas diretas, muitas vezes \\
& monossilábicas; \\
& - não revelam interesse em expandir o diálogo com o texto; \\
& - demonstram dificuldades com uso de nexostextuais na construção das respostas; \\
& - revelam muitos problemas quanto ao uso das convenções ortográficas: regulares diretas \\
& (p/b; t/d; f/v); regulares contextuais (m/n antes de consoante; r/rr; s/ss); regulares \\
& morfológico-gramaticais (am/ão; u/l em final de verbo) e irregulares (s/z; c/ss). \\
\cline { 2 - 3 } & Posterior às ações colaborativas \\
& - A maior parte dos alunos consegue localizar informações, realizar inferências, distinguir \\
\hline
\end{tabular}




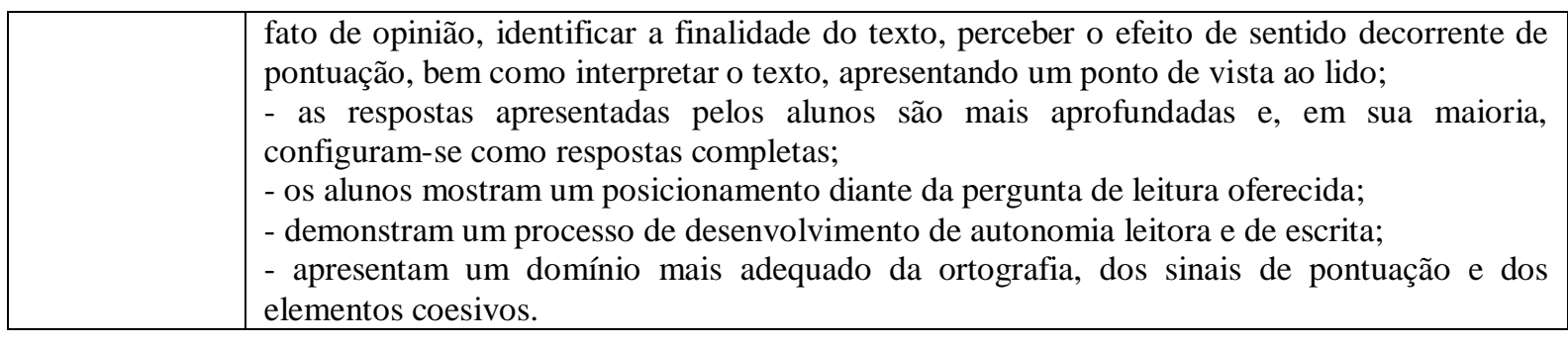

Fonte: organizado pelos autores.

Posteriormente às ações colaborativas, os alunos mostram-se leitores e produtores de textos mais competentes e críticos. Quanto à leitura, interagem com o texto, reconhecendo informações textuais, produzindo inferências, elaborando interpretações, avançando no processo leitor. Assim, as réplicas ao texto lido mostram-se mais críticas e criativas, dentro dos limites que esses alunos poderiam expressar. Quanto à produção escrita, os alunos escrevem com mais criatividade e de modo mais condizente com a escrita padrão. Por essas atitudes, demonstram um uso mais eficaz da linguagem escrita e, assim, têm maiores condições de lidar com os textos das diferentes disciplinas do currículo escolar e estender o tempo de escolaridade.

\section{Considerações finais}

Constatamos que as práticas em SAALP, após as ações colaborativas, aproximam-se mais dos pressupostos da concepção dialógica de linguagem. Nesse sentido, os encaminhamentos pedagógicos em SAA passam a propiciar condições para que, por meio da leitura, o aluno dialogue com o texto lido, reconhecendo informações, inferenciando e interpretando, assumindo, assim, uma posição responsiva ativa frente aos enunciados e desenvolvendo sua autonomia leitora; por meio das práticas de produção textual, as ações pedagógicas, balizadas pelos princípios interativos inerentes à escrita, buscam que o aluno elabore textos levando em conta a produção escrita como uma ação direcionada para o outro e para uma finalidade específica.

Esses encaminhamentos foram obtidos a partir do arcabouço teórico-metodológico que sustentou a investigação. Os alicerces acerca dos processos de leitura e escrita (MENEGASSI, 2001a; 2010b) permitiram que o professor entendesse a necessidade de e como auxiliar o aluno a construir-se progressivamente como sujeito leitor e produtor de textos, capaz de produzir suas próprias palavras na leitura e na produção textual (BAKHTIN/VOLOCHINOV, 1999[1929]). Os conhecimentos dos processos de leitura foram internalizados e apropriados pelo professor no interior das relações sociais - nas interações com a pesquisadora, com os alunos da SAALP, com os signos e os diversos instrumentos que permearam as ações colaborativas, demonstrando a importância das discussões propiciadas pela teoria históricocultural (VYGOTSKY, 1994; 1998) e dos postulados da pesquisa colaborativa que tornaram as relações entre professor e pesquisadora um espaço de coconstrução de conhecimentos, pondo-se a serviço da constituição da autonomia, emancipação e desenvolvimento do professor.

\section{Referências}


ANGELO, C. M. P. Atividades de leitura no caderno Orientações Pedagógicas para as Salas de Apoio à Aprendizagem. In: CONGRESSO DE LEITURA DO BRASIL - COLE, 16., 2007, Campinas. Anais... Campinas, 2007. Disponível em: <http://alb.com.br/arquivomorto/edicoes_anteriores/anais16/sem11pdf/sm11ss13_05.pdf >. Acesso em: 15 fev. 2012.

; FRACASSE, L. O interlocutor nos comandos de produção escrita. In: CARAZZAI, M. R. P; TEIXEIRA, N. C. R. B.; GONÇALVES, R. (Orgs.). Língua, leitura e literatura: perspectivas de ensino. Guarapuava: UNICENTRO, 2009. p. 81-96.

BAKHTIN, M. M. Estética da criação verbal. Tradução do russo por Paulo Bezerra. 4.ed. São Paulo: Martins Fontes, 2003 [1979].

; VOLOCHINOV, V. N. Marxismo e filosofia da linguagem: problemas fundamentais do método sociológico na ciência da linguagem. Tradução do francês por Michel Lahud e Yara Frateschi Vieira. 9.ed. São Paulo: Hucitec, 1999 [1929].

BRASIL, Secretaria de Ensino Fundamental. Parâmetros Curriculares Nacionais de Língua Portuguesa, $3^{\circ}$ e $4^{\circ}$ Ciclos do Ensino fundamental. Secretaria de Educação Fundamental. Brasília - MEC/SEF, 1998.

DUARTE, P. C. de O. A produção textual na sala de apoio à aprendizagem de língua portuguesa: uma análise das condições de produção no Caderno Orientações Pedagógicas. 2011. Dissertação (Mestrado em Letras) - Programa de Pós-graduação em Letras, Universidade Estadual de Maringá, Maringá, 2011. Disponível em: <http://www.ple.uem.br/defesas/def_patricia_duarte.htm>. Acesso em: 20 jan. 2012.

GATti, B. A.; BARReto, E. de S.; ANDRÉ, M. E. D. A. Políticas docentes no Brasil: um estado da arte. Brasília: UNESCO, 2011.

IMBERNÓN, F. Formação continuada de professores. Porto Alegre: Artmed, 2010.

LOUREIRO, M. I. O desenvolvimento da carreira dos professores. In: ESTRELA, M.T. (Org.). Viver e construir a profissão docente. Porto Alegre: Porto Editora, 1997. p. 117-159.

MATTOS, A. M. A colaboração e confiança na formação do professor de línguas estrangeiras. Signum: Estud. Ling., Londrina, v.10, n.1, p. 11-32, jul. 2007.

MENEGASSI, R. J. O leitor e o processo de leitura. In: GRECO, E. A.; GUIMARÃES, T. B. (Orgs.) Leitura: aspectos teóricos e práticos. Maringá: Eduem, 2010a.p. 35-59.

O processo de produção textual. In: SANTOS, A. R. dos; GRECO, E. A.; GUIMARÃES, T. B. (Orgs.) A produção textual e o ensino. Maringá: Eduem, 2010b. p. 75101.

MORTATTI, M. do R. L. Educação e letramento. São Paulo: UNESP, 2004.

OLIVEIRA, M. K. de. Vygotsky: aprendizado e desenvolvimento: um processo sóciohistórico. 4.ed. São Paulo: Scipione, 2006. 
PIMENTA, S. G. Pesquisa-ação crítico-colaborativa: construindo seu significado a partir de experiências com a formação docente. Educação e Pesquisa, São Paulo, v. 31, n. 3, p. 521 539, set./dez. 2005.

RODRIGUES, A. Perguntas de leitura e construção de sentidos: experiência com o $6^{\circ}$ ano do Ensino Fundamental. 2013. Dissertação (Mestrado em Letras) - Programa de PósGraduação em Letras, Universidade Estadual de Maringá, Maringá, 2013. Disponível em: $\langle$ http://www.ple.uem.br/defesas/def_adelia_aparecida_pereira_da_silva_rodrigues.htm $>$.

Acesso em 10 jan. 2014.

SILVEIRA, A. P. K. da. Formação continuada em língua portuguesa: crenças, expectativas e saberes. In: CONGRESSO NACIONAL DE EDUCAÇÃO - EDUCERE, 9.; ENCONTRO SUL BRASILEIRO DE PSICOPEDAGOGIA, 3., Curitiba, 2009. Anais... Curitiba: PUCPR, $2009 . \quad$ Disponível em: <http://www.pucpr.br/eventos/educere/educere2009/anais/pdf/3474_1945.pdf >. Acesso em: 19 abr. 2014.

SOLÉ, I. Estratégias de leitura. Tradução de Claudia Schilling. Porto Alegre: Ed. Artmed, 1998.

VYGOTSKY, L. S. A formação social da mente: o desenvolvimento dos processos psicológicos superiores. Organizadores Michael Cole.. [et al.]. Tradução José Cipolla Neto, Luis Silveira Menna Barreto, Solange Castro Afeche. 5. ed. São Paulo: Martins Fontes, 1994.

Pensamento e Linguagem. Tradução Jefferson Luiz Camargo. 2. ed. São Paulo: Martins Fontes, 1998. 